\title{
A POLÍTICA DE ASSENTAMENTOS RURAIS DO GOVERNO FHC E OS DESAFIOS DA REFORMA AGRÁRIA NO BRASIL DO SÉCULO XXI
}

\section{Paulo Roberto R. Alentejano}

Geógrafo, Prof. da UERJ, Doutor pelo CPDA/UFRRJ.chinelo@uninet.com.br

\section{RESUMO}

O texto procura caracterizar a política de FHC como anti-popular e neoliberal em relação à reforma agrária, tendo como referência a dependência externa, a privatização às custas do Estado, a priorização do sistema financeiro, o aumento das desigualdades sociais e o aumento do desemprego.

O texto trata, ainda, dos desafios da reforma agrária no século XXI.

\section{PALAVRAS-CHAVE:}

Reforma agrária, Agricultura, Política agrária, Estado, Campo.

\section{ABSTRACT}

The text aims to characterize FHC's policy as anti-popular and neo-liberal with relation to agrarian reform, having as reference the external dependence, the privatization at the State's expense, the financial system as a priority, growing of social inequalities and growing of unemployment.

The text approaches also the challenges for agrarian reform in the twenty-first century.

\section{KEYWORDS}

agrarian reform, agriculture, agrarian policy, State, countryside.

1. O projeto de FHC e o lugar da reforma agrária

É comum ouvirmos dizer que o governo FHC é neoliberal e muitas vezes o repetimos, sem definirmos exatamente o que queremos dizer com isso. Tentaremos resumir brevemente as características centrais que dão à política de FHC um sentido anti-popular e neoliberal e relacioná-la com a questão da reforma agrária. 
O primeiro aspecto central da política de FHC é o aumento da dependência externa, baseada em quatro elementos: eliminação praticamente absoluta das restrições às importações (inclusive de produtos agrícolas); abertura para a entrada maciça do capital estrangeiro, particularmente os de natureza especulativa, provocando forte vulnerabilidade; crescimento da dívida externa, apesar do pagamento de juros crescentes; entrega do patrimônio nacional ao capital estrangeiro através do processo de privatização. Somados, estes processos se traduzem num aumento da vulnerabilidade brasileira frente às grandes empresas transnacionais e às principais potências estrangeiras, particularmente, os EUA.

O segundo é a privatização realizada às custas do Estado. Não bastasse entregar um enorme patrimônio construído a partir dos esforços públicos e financiado pelos impostos pagos pela população, o governo o faz de forma inacreditavelmente barata: aceita moedas podres, ou seja, títulos públicos cujo valor nominal (teórico) é muito maior que o real (efetivo); financia a compra das empresas privatizadas através do BNDES, com prazos e condições de pagamento extremamente favoráveis, o que resulta em algo curioso, para não dizer revoltante, isto é: o governo que alegava não ter recursos para continuar mantendo e investindo nas empresas estatais, empresta, de forma subsidiada, dinheiro para as empresas privadas nacionais ou estrangeiras comprarem as empresas que eram do governo...

O terceiro aspecto central desta política é a prioridade dada ao sistema financeiro, beneficiado por um amplo programa de reestruturação, o PROER, que injetou mais de 20 bilhões de dólares no setor, e, por uma política de juros altos que faz com que o governo transfira para este setor um valor anual aproximado de 50 bilhões de dólares por ano.

O quarto é o aumento das desigualdades sociais, resultante do aumento dos lucros das empresas e da queda da renda dos trabalhadores. Enquanto a lucratividade das empresas aumenta, em função da adoção de novas tecnologias, do enxugamento de seu quadro de funcionários, da cassação de direitos trabalhistas, o rendimento dos trabalhadores cai, pressionado pelo aumento do desemprego, pela redução dos direitos trabalhistas e pela queda dos preços agrícolas.

Finalmente, o quinto aspecto central desta política anti-popular é a explosão do desemprego, que atinge, hoje, 1 em cada 5 trabalhadores e é provocada pela abertura da economia - que produz falência de indústrias e quebra de pequenos e médios agricultores -, pela política de juros altos - que desestimula investimentos produtivos e 
direciona recursos para a especulação financeira - e pelas privatizações - que promovem enxugamento do quadro de funcionários de antigas empresas estatais.

Estes são os cinco aspectos centrais que dão à política de FHC um caráter antipopular e permitem que a definamos como neoliberal, tendo provocado um verdadeiro desmonte da nação1. Ora, um projeto de natureza tão antagônico aos interesses das classes populares não pode ter entre seus elementos uma política de reforma agrária. Analisemos mais detidamente suas características no que se refere à área rural.

2. A propaganda e a realidade da" reforma agrária" e da agricultura no governo FHC

Da mesma forma que tenta falsear a realidade propagandeando supostos aspectos positivos das privatizações, do PROER e da abertura econômica e é capaz até de negar o crescimento do desemprego, o governo tenta colocar a reforma agrária como grande realização. Três exemplos desta tática propagandística são: (1) a publicidade veiculada na televisão em que um ator famoso afirmava que o governo assentava 1 família a cada cinco minutos. Ora, considerando que há 4,8 milhões de famílias sem terra, seriam necessários 48 anos para resolver o problema, caso não surgisse mais nenhuma família no país...; (2) a afirmação de que esta é a maior reforma agrária da história, com 16 milhões de hectares desapropriados. Ora, isto representa apenas 14\% de todas as terras ociosas do país, segundo o próprio INCRA e somente 5\% de todas as terras em poder do latifúndio no Brasil. Bela reforma agrária...; (3) A afirmação de que o crédito oferecido aos assentados é amplamente subsidiado não se sustenta, pois, conforme cálculos do economista Fernando Homem de Mello (1999) comparando-se os custos de financiamento e a evolução da inflação observamos que a taxa de juros para os agricultores familiares que era 20\% inferior à inflação em 1995 passou a ser 260\% maior em 1998. Além disso, a oferta de crédito tem diminuído.

Por outro lado, estudos e declarações do próprio governo dão uma amostra mais efetiva do que é seu intento: (1) seu principal ministro, Malan, declarou repetidamente e pesquisadores ligados ao governo buscaram demonstrar que o futuro do campo brasileiro é ter cerca de 600 mil estabelecimentos agropecuários e apenas 5\% da população trabalhando na agricultura, cabendo aos miseráveis do campo uma política de

\footnotetext{
${ }^{1}$ Aproveito-me aqui da expressão que dá nome a dois livros lançados recentemente por LESBAUPIN (2000) e LESBAUPIN e MINEIRO (2002).
} 
distribuição de cestas básicas, ou coisa que o valha.2; (2) o ministro da Agricultura, cuja preocupação praticamente exclusiva é promover as exportações, vem sustentando que a agricultura brasileira deve se especializar na produção daqueles produtos com melhor mercado internacional, importando os demais, o que certamente significaria a eliminação de qualquer política de apoio à agricultura familiar. Isto já pode ser observado objetivamente, pois os preços dos produtos produzidos pelos agricultores familiares apresentaram queda anual de 47,4\% nos últimos 10 anos, segundo cálculos de Mello.

Assim, o que temos hoje no meio rural brasileiro, muito longe de ser "a maior reforma agrária do mundo” é uma precária política de assentamentos rurais, pelas razões que se seguem:

1. Grande parte dos assentamentos é na realidade regularização fundiária, isto é, não se trata de desapropriação de terras para assentar pessoas que não tenham acesso a esta, mas concessão de títulos definitivos para posseiros que há muito ocupavam tais áreas - o que fica claro quando observamos que cerca de $75 \%$ dos assentamentos realizados nos últimos 8 anos situam-se nas regiões Norte e Centro-Oeste, portanto, na fronteira agrícola brasileira;

2. Ao mesmo tempo em que se constitui um expressivo número de assentamentos rurais3 - em comparação com governos anteriores em que quase nada era feito - está em curso um amplo processo de expulsão de pequenos produtores do meio rural (menos 1 milhão de estabelecimentos agrícolas entre 1985 e 1996 e falência de 500 mil pequenos produtores rurais entre 1995 e 2000), dadas as condições desfavoráveis em termos de preços agrícolas (32\% desde a implantação do real em 1994), ausência de apoio técnico e creditício, precariedade da estrutura de armazenamento e escoamento da produção, processos agravados pela abertura indiscriminada da economia (aumento de 700\% nas importações agrícolas) e pelo desmonte do aparelho estatal de pesquisa e extensão, o que faz com que o número de famílias que perdeu a terra supere as beneficiadas pelos assentamentos, mesmo que contabilizássemos todas estas como novas beneficiárias;

\footnotetext{
““A baixa remuneração da agricultura, combinada com a atração das cidades, está levando a um esvaziamento dos campos. Prevalecendo a atual situação, estamos no caminho de uma agricultura que abrigará apenas 600 mil estabelecimentos dos atuais 4,9 milhões.” - ALVES et al: 1999: 32. Vale dizer que estes autores não estão criticando, mas elogiando quando fazem tais considerações.

${ }^{3}$ Embora os números do Ministério do Desenvolvimento Agrário sejam em geral superestimados, com famílias contadas mais de uma vez (quando há a desapropriação e quando são efetivamente assentadas), consideração da capacidade de assentamento e não do contingente efetivamente assentado, com a contagem de famílias que foram apenas cadastradas e jamais foram efetivamente assentadas, como denunciado por documento da ABRA. Ver TEIXEIRA (2000).
} 
3. As ações de desapropriação e compra de terras pelo governo não obedecem a uma lógica prévia e estrategicamente programada, mas são resultado da pressão dos movimentos sociais e representam respostas localizadas com vistas a evitar a propagação de conflitos sociais no campo;

4. A criação do mecanismo de compra de terras representa um retrocesso - além de mais um exemplo da malfadada generalização da idéia de que o mercado resolve tudo -, pois, premia os interesses especulativos, dando a esses a possibilidade de realizar a renda da terra, quando reforma agrária pressupõe punir os que retêm a terra com este fim;

5. A criação de assentamentos não é acompanhada de medidas que garantam às famílias condições efetivas de produção, comercialização e melhoria das condições de vida, uma vez que as obras de infra-estrutura - produtiva e social - necessárias não são realizadas na maior parte dos assentamentos criados.4 Não há estradas para escoamento da produção, não há assistência técnica, ou esta é precária, não há escolas nem postos de saúde, ou há, mas não funcionam;

6. Não há uma reformulação da política agrícola que passe a privilegiar a pequena produção familiar, perpetuando-se, portanto, as condições que produzem a concentração fundiária e reafirmando-se o modelo da grande produção, para onde convergem os recursos públicos de financiamento da agricultura. Como comprovação disto, vemos que, entre os Censos Agropecuários de 1985 e 1996, a área cultivada diminuiu 8 milhões de hectares, a produção agrícola cresceu menos $11 \%$ que a população, aumentando a fome, o crédito caiu de 19 bilhões ao ano para 8 bilhões, a venda de tratores caiu de 37 para 17 mil ao ano. Por outro lado, o governo liberou 45 bilhões para os usineiros, 2,5 bilhões para as grandes cooperativas, parcelou em 20 anos com 9\% de juros/ano as dívidas de 3 mil grandes proprietários com o Banco do Brasil, num total de 4,5 bilhões e está investindo 20 bilhões em corredores de exportação de soja e outros grãos;

Tudo isto nos faz afirmar que não há reforma agrária em andamento no Brasil, mas uma política de assentamentos rurais, resultado da pressão dos movimentos sociais, mas que cada vez mais se transforma em instrumento do governo contra os mesmos movimentos sociais que a impulsionaram com sua luta.

\footnotetext{
${ }^{4}$ Conforme atestou inclusive reportagem da Folha de São Paulo de 21 de abril de 2002.
} 
3.Os fundamentos políticos da "Nova Reforma Agrária” do governo FHC II

A formulação por parte do Governo Federal de uma política explicitamente voltada para a agricultura familiar, colocando-a no centro das propostas de desenvolvimento rural é fruto de uma confluência de pressões, assim como da tentativa do Governo de reverter o quadro politicamente desfavorável em que o mesmo foi posto em seu primeiro mandato do ponto de vista da questão agrária, como resultado da combinação da ofensiva dos movimentos sociais rurais - especialmente o MST, mas também a CONTAG e seu “Grito da Terra” - e da crescente pressão internacional diante de episódios como as chacinas de Corumbiara e Eldorado dos Carajás.

Segundo Carvalho $\mathrm{F}^{\mathrm{o}}$ (2001), pressionado pela repercussão internacional do Massacre de Carajás, o governo decidiu criar o Ministério Extraordinário de Política Fundiária e com o sucesso da Marcha Nacional, o governo foi obrigado a agir mais concretamente em relação à questão agrária, embora esta decisão não tivesse sido consensual. O então ministro da Justiça, Íris Rezende, pregava o fortalecimento da aliança com os fazendeiros na repressão aos Sem Terra, lamentando inclusive que o governo federal não tenha dado mais sustentação ao governo do Pará por ocasião do Massacre de Eldorado de Carajás. (Carvalho Fo , 2001: 207)

Tais divergências refletem-se inclusive nas próprias formulações políticas governamentais, pois a proposta constante do documento "Agricultura Familiar, Reforma Agrária e Desenvolvimento Local para um Novo Mundo Rural - Política de Desenvolvimento Rural com Base na Expansão da Agricultura Familiar e sua Inserção no Mercado” lançado em março de 1999, propõe um novo tipo de desenvolvimento rural em flagrante contraste com o padrão de agricultura incentivado até então pelo próprio governo, a produção monocultora em larga escala para exportação, ou, para utilizar termos mais na moda, o “agribusiness”, ou agronegócio.

Concorre também para esta valorização - ao menos retórica - da agricultura familiar, a crise do setor agropecuário modernizado. O documento é explícito neste sentido ao apontar para o esgotamento do modelo de industrialização concentrada e da agricultura patronal. De acordo com o “novo ideário governista”, a concentração de riqueza e renda prejudica o desenvolvimento econômico e o modelo agrícola dominante no país durante as últimas décadas contribuiu para tanto, sendo portanto necessário 
romper com esta herança para superar os obstáculos à retomada do crescimento econômico.5

Outro aspecto que chama atenção nas formulações governamentais e que é indicativo dos fundamentos que regem a adoção de tal política, diz respeito à proposta de unificação das políticas de crédito e assistência técnica “para uma melhor alocação de recursos escassos” (Ministério do Desenvolvimento Agrário, 1999: 2).

Fica claro aqui o caráter dominante nas formulações governamentais dos “aspectos técnicos”, eufemismo para designar a racionalidade economicista que impera, mesmo que envolta em belas análises e justificativas teórico-conceituais muitas vezes antagônicas. Entretanto, quando analisamos o conjunto do documento, bem como as ações governamentais no setor e a conjuntura política mais ampla, chama atenção o caráter estratégico desta nova política do ponto de vista de enfrentamento da questão agrária e particularmente, a tentativa de acuar o MST.

Diante da incapacidade de derrotar politicamente o MST durante o primeiro mandato, o governo FHC decidiu alterar suas táticas. Se antes as armas eram a propaganda das ações do INCRA e a crítica aos métodos do MST - visando convencer a população de que o governo estava fazendo sua parte e o MST era radical6 - a partir deste momento, o governo muda suas armas, passando a centrar suas ações em duas frentes: intensificação da repressão, através da criminalização das ações do movimento e da perseguição de suas lideranças; alteração das regras da política de obtenção de terras e de financiamento da produção, de modo a minar as duas fontes básicas de oxigenação do movimento, qual sejam, a concretização da desapropriação das terras ocupadas e o bom desempenho de alguns assentamentos vinculados ao MST, diante da situação de penúria generalizada da agricultura familiar.

A criminalização das ações do MST e demais movimentos de luta pela terra, consubstancia-se através da perseguição de suas lideranças, da proibição das entidades envolvidas em ocupações de imóveis rurais ou bens públicos de receber recursos públicos e dos cidadãos envolvidos em ocupações de terras ou prédios públicos serem beneficiárias de assentamento. No mesmo sentido, há uma clara tentativa de desarticular

\footnotetext{
${ }^{5}$ Vale lembrar aqui a já referida separação dos ministérios da Agricultura e do Desenvolvimento Agrário. Certamente esta posição não coincide com a do Ministro da Agricultura, defensor do agribusiness e da agroexportação.

${ }^{6}$ Neste sentido, aliás, o governo acaba de receber enorme contribuição de um dos mais importantes estudiosos da questão agrária brasileira, José de Souza Martins, que em texto recentemente publicado faz uma enfática defesa da política do governo para o setor, acusando o MST, a Igreja e as "oposições" de intransigência.
} 
o movimento e desmobilizar os sem terra, com medidas como a proibição por dois anos (dobrando em caso de reincidência) da vistoria de latifúndios ocupados. Além disso, latifúndios improdutivos inscritos no programa de arrendamento de terras não podem mais ser desapropriados.

De outro lado, o governo altera as regras de financiamento dos assentados, sob os argumentos de que assentados são iguais a agricultores familiares e seria uma injustiça para com estes últimos dar melhores condições para os primeiros7.

O argumento governamental centrava-se no fato de que a ampliação do número de assentados criou dois problemas: inviabilidade financeira do PROCERA e incapacidade do INCRA controlar os assentados. De acordo com esta perspectiva, os assentados de 1995 a 1998 deviam 5,8 bilhões de reais em terra e créditos e estimava-se que o débito do conjunto dos assentados seria de 8 bilhões de reais. Esta dívida, entretanto, não podia ser cobrada, dadas as dificuldades para a titulação e emancipação, para o que o governo propõe como alternativa a redução das exigências formais para a emancipação.

Assim, conforme Carvalho $\mathrm{F}^{o}$ (2001), o “sucesso" do programa de assentamentos do primeiro governo é usado como argumento para mudá-lo propondo-se como alternativa a descentralização, a obtenção de terras via mercado e o fim do “paternalismo” em relação aos assentados.

Para isto, propõe a aceleração do processo de emancipação dos assentamentos (reduzindo os requisitos para isto à execução dos serviços topográficos, à abertura de estrada de acesso e a existência de condições habitacionais satisfatórias), para fazer os assentados pagar pela propriedade da terra (previsão de entrega aos beneficiários dos títulos de propriedade, com prazo de 20 anos para pagar a terra, com carência de 3 e juros de 6\% a. a. para os novos assentados; 18 anos com 3 de carência para os criados entre 1995 e 1998; e 15 anos, com carência de 2, e juros de 6\% a. a., para os mais antigos).

Ora, ter que pagar junto o crédito e a terra certamente será impossível para a maioria dos assentados, o que fará com que muitos vendam a terra. É isto que o governo quer para poder depois dizer que não dá certo fazer reforma agrária porque depois os sem terra vendem a terra, pois são incapazes. É também expressão deste processo em

\footnotetext{
${ }^{7}$ Interessante observar que diante da avaliação de que não há diferenças entre as duas categorias e de que os primeiros tinham até então uma política mais favorável, estabelece-se como política para ambas a até então existente para os últimos, ou seja, a considerada menos favorável, o que poderia ser definido como um caso explícito de "socialização da injustiça”, coerente com o ajuste neoliberal.
} 
que o Estado se livra de suas obrigações para com os trabalhadores e busca atribuir a estes toda a responsabilidade por seu destino, como se as condições gerais fossem favoráveis para isto, como se o ambiente econômico não fosse o do neoliberalismo que só beneficia os mais ricos.

Por outro lado, as novas normas de implantação dos assentamentos são uma forma de aumentar o controle do Estado sobre os assentados, buscando limitar a influência dos movimentos sociais sobre os trabalhadores que lutam pela terra. A necessidade de que os sem terra assinem um documento concordando com o preço da terra e as condições dos recursos naturais do imóvel como pré-condição para o assentamento é um dos principais instrumentos desta nova estratégia. Do mesmo modo, a imposição da criação de entidade(s) de representação com responsabilidade judicial para que se dê a liberação dos recursos para elaboração do Plano de Desenvolvimento do Assentamento (PDA), execução da topografia, compra do material para construção das habitações e construção da infra-estrutura (estradas, água e energia), tarefas até então sob a responsabilidade estatal (do INCRA) fazem parte do processo de desmonte do Estado e criação de uma nova forma de controle social sobre os movimentos sociais.

Como resultado deste conjunto de políticas, houve expressiva redução das desapropriações: de 1998 para 1999 houve redução de 48,4\% na área desapropriada e de 59,8\% na capacidade de assentamento e de 1999 para 2000 nova redução de 42,8 e $59,4 \%$ respectivamente. 8

Por outro lado, ao eleger o Banco da Terra como instrumento fundamental de obtenção de terras e propor a descentralização das ações fundiárias, transferindo a maior parte da responsabilidade para o âmbito municipal - num país tradicionalmente marcado pelo poder das oligarquias locais -, o governo não só busca desarticular o movimento, apostando na incapacidade deste de se contrapor ao poder local, como aposta na desmobilização dos sem terra, pois oferece - teoricamente - a possibilidade de obtenção de terra sem necessidade de mobilização, pressão política e tampouco sacrifícios.9

\footnotetext{
${ }^{8}$ Se considerarmos as distorções nos números de famílias assentadas apontadas pelo estudo da ABRA supra citado a redução seria ainda mais expressiva. Ver TEIXEIRA (2002).

${ }^{9}$ São inúmeros os relatos de militantes do MST dando conta das dificuldades crescentes de mobilizar trabalhadores para ocupações diante da pregação de políticos locais e dirigentes sindicais que dizem para as famílias sem terra coisas como: "Não precisa se meter nesse negócio de invasão, que é ilegal e perigoso. Basta colocar seus dados neste papel que o governo vai comprar uma terra e dar para você...”. Mais uma vez, é surpreendente que MARTINS (2000) seja tão otimista em relação ao processo de descentralização da reforma agrária, especialmente sendo ele autor de inúmeros trabalhos que demonstram a capacidade das classes dominantes brasileiras - e dos latifundiários em particular - de controlar a política local e redirecionar os processos de transformação social em benefício próprio.
} 
“O Banco da Terra tem o objetivo estratégico de desqualificar os movimentos sociais organizados - especialmente deslegitimar o MST - atuando diretamente no âmbito econômico dos trabalhadores desorganizados. Assim, provocaria mudanças na correlação das forças políticas e ideológicas envolvidas na luta pela terra, beneficiando os interesses dos latifundiários e subordinando os trabalhadores rurais.As invasões seriam retidas, os latifundiários receberiam dinheiro a vista por terras $e$ benfeitorias, e os trabalhadores ficariam sob o domínio das oligarquias locais, liberadas do respeito à função social da propriedade rural.” (CARVALHO Fº, 2001: 223).

Além disso, o Banco da Terra representa a possibilidade da realização imediata da renda fundiária pelos proprietários de terra, principalmente aqueles que adquiriram terra nos anos 70, quando o crédito subsidiado representava enorme atrativo para o capital industrial e financeiro, uma vez que permitia o acesso a recursos baratos e fartos, ao mesmo tempo em que significava proteção contra as oscilações da economia.

No contexto atual, em que a terra perdeu valor como ativo financeiro e não há mais oferta de crédito farto e barato para o setor agropecuário, interessa a alguns grupos econômicos se desfazer das terras outrora adquiridas. Esses grupos aos quais antes interessava oferecer as terras ao INCRA para que fossem desapropriadas, agora não mais têm interesse nisto, uma vez que as possibilidades de utilização dos TDAs10 no processo de privatização encontra-se hoje praticamente esgotada. Assim, o Banco da Terra aparece como interessante alternativa de realização imediata da renda fundiária.11 Conforme, Carvalho Fo:

“O Banco da Terra beneficia o proprietário de terras que ignora a exigência constitucional do cumprimento da função social da propriedade rural. Ou seja, retira o caráter punitivo da legislação sobre o latifúndio e desqualifica uma importante

\footnotetext{
${ }^{10}$ Os Títulos da Dívida Agrária, uma das famosas “moedas podres”, eram aceitos pelo valor de face nos processos de privatização, o que levou muitas empresas, principalmente bancos, a se utilizar destas para comprar empresas estatais, porém, hoje esta possibilidade está muito restringida, dado que falta vender muito pouco do patrimônio público.

${ }^{11}$ Não podemos deixar de criticar a posição de MARTINS [1999], para quem “A política fundiária tem por objetivo atenuar e circunscrever o rentismo, atenuado, portanto, pela própria reforma agrária, gostem dela ou não os opositores do governo.”. Parece-nos que ao contrário de atenuar, a nova política vem no sentido de reforçar o rentismo, permitindo a realização imediata da renda fundiária e a própria elevação desta.
} 
conquista social dos trabalhadores. Além disso, também possibilita manipulações nos empréstimos beneficiando o latifúndio.” (CARVALHO Fo , 2001: 217).

Não à toa, as entidades patronais rurais louvaram a criação do Banco da Terra, conforme fica evidente na afirmação de Ernesto de Salvo, presidente da CNA, reproduzida em Medeiros (2002).

"Isso é tudo que o setor rural brasileiro queria em matéria de reforma agrária no Brasil; ... estamos saindo de um regime no qual imperavam as invasões, as querelas judiciais sobre desapropriações ou produtividade dos imóveis rurais, que demandavam tempo, arbitrariedades e violências, e passando para um meio moderno de aquisição e financiamento de terras (...) às pessoas que possuem vocação para trabalhar na terra, caso dos trabalhadores rurais assalariados, parceiros, arrendatários e minifundistas, incluindo aí os filhos de pequenos agricultores ou mesmo aqueles que perderam suas propriedades. É um avanço importante em relação ao programa de assentamentos, que simplesmente coloca nas propriedades pessoas que não têm nenhuma familiaridade com o trabalho rural e tornam-se eternos dependentes do Governo". (MEDEIROS, 2002: 57).

Ou seja, depreende-se de tudo isto que por trás das belas palavras que emolduram o discurso governamental para o setor, emerge uma visão tecnicista e economicista acerca do processo de reforma agrária que enxerga apenas seus custos diretos e imediatos e, mais importante do que isto, uma concepção de classe que objetiva provar que a reforma agrária é uma política cara, ineficiente e ultrapassada.

Afinal, a política do governo FHC:

“...não altera a estrutura fundiária. Ao contrário, ao desapropriar pontual e ocasionalmente terra por interesse social para fins de reforma agrária ou adquiri-las por compra no âmbito de uma política de crédito fundiário, a política de assentamentos dos governos de FHC transformou terras economicamente marginalizadas em ativos financeiros (dinheiro ou títulos da dívida agrária) para o benefício dos latifundiários.” Carvalho, 2002: 1. 
Portanto, a análise da conjuntura atual e sua relação com a reforma agrária nos mostra que o governo FHC mudou sua tática de enfrentamento e escolheu outros campos de disputa, resultando num efetivo reposicionamento do debate acerca do tema no país, mas cujo pano de fundo é a reafirmação do domínio do campo brasileiro pelo grande capital.

\section{Os desafios da reforma agrária no século XXI}

Os termos que marcavam o debate sobre a reforma agrária - que já haviam sido alterados entre os anos 60 e 80, em função das transformações no meio rural brasileiro alteraram-se substancialmente, colocando ao menos quatro questões: (1) a decretação da extinção do rural e da inevitabilidade da urbanização, postulado sustentado pelo governo, em coerência inclusive com o programa analisado neste texto, afinal, como vimos, este aposta num pequeno segmento de "agricultores profissionais" e não numa reforma agrária massiva; (2) a afirmação da capacitação individual dos agricultores e da qualificação para a disputa de mercado como saída para a agricultura familiar; (3) a afirmação da "reforma agrária de mercado" como o mecanismo mais eficaz para distribuir terra no campo; (3) a afirmação de que a melhor forma de garantia da posse da terra no campo é a propriedade privada por parte dos pequenos agricultores.

A resposta a estes desafios deve se pautar pelos seguintes princípios:

1. Ao contrário de apostar na urbanização como futuro da organização do espaço brasileiro, devemos nos pautar pela ruptura da dicotomia campo-cidade, através da multiplicação nos assentamentos rurais e nas pequenas cidades da infra-estrutura e dos serviços vistos até o momento como sinônimos de urbanização. Assim, o fenômeno da pluriatividade12 deve ser encarado como uma forma de expandir no campo mecanismos de geração de renda alternativos à agricultura, mas também, de difusão de atividades geradoras de conforto para a população rural.

2. Em contrapartida à aposta individualista na capacitação para a competição no mercado, devemos pensar a capacitação para a cooperação e o exercício da

\footnotetext{
${ }^{12}$ A polêmica sobre a questão da pluriatividade tem se alastrado entre os estudiosos da questão agrária brasileira, com alguns sustentando ser esta expressão da modernização do meio rural brasileiro e, outros, resultado do atraso. Reafirmo aqui a concepção por mim expressa em artigo anterior (ALENTEJANO, 1999) em que a considero resultado contraditório do desenvolvimento do capitalismo brasileiro, portanto, ao mesmo tempo, expressão da modernização em curso neste e do atraso aí persistente.
} 
solidariedade, fazendo dos assentamentos espaços não apenas de cooperação interna na produção, mas de exercício de solidariedade em relação à população de seu entorno.

3. Outro desafio central está na formulação de um modelo de desenvolvimento sustentável, ou seja, na criação e na implementação de um modelo de desenvolvimento capaz de gerar renda e alimentos suficientes para a garantia de uma boa qualidade de vida para a população assentada, mas também de garantir a qualidade dos alimentos produzidos, a preservação (ou recuperação) ambiental. Neste sentido, os assentamentos deverão se constituir também em espaços de ecoturismo popular, ou seja, em áreas onde a preservação do ambiente seja parte do modo de vida dos assentados e contra-exemplo à tendência dominante de apropriação privada do que resta de recursos naturais preservados.

4. O maior desafio - porque fundamentalmente ideológico - está no enfrentamento do conjunto de idéias mercadológicas que têm se tornado dominantes nos debates sobre a reforma agrária. Neste sentido, são desafios: retomar o princípio de que os especuladores devem ser punidos por manterem a terra improdutiva, dados os custos que isso gera para a sociedade e a injustiça presente neste fato; recolocar em pauta o confisco das terras improdutivas, exploradas com base em trabalho escravo e outras formas ilegais, negando as desapropriações e a compra de terras, por seu caráter de prêmio aos especuladores e aos latifundiários; retomar o debate acerca do estabelecimento de limites máximos para o tamanho das propriedades, como base para a geração de uma melhor distribuição de riqueza e renda no país; recolocar o debate acerca da melhor forma de titulação da terra, negando a proposta imposta hoje de forma unilateral pelo governo de distribuição de títulos de propriedade, e afirmando o princípio da garantia da terra pública e de seu usufruto em benefício da sociedade.

Desenvolver argumentos que sustentem tais posições e difundir na sociedade estas idéias é o desafio que se coloca neste momento para intelectuais comprometidos com a luta pela terra, a reforma agrária e a transformação da sociedade, cientes de que se trata de um debate de profunda conotação ideológica, como sempre foi o debate em torno da reforma agrária, apesar da cantilena governamental e seus ideólogos que por trás da propaganda da desideologização e despolitização da reforma agrária, buscam mercantilizá-la. E isto é profundamente ideológico.

\section{Bibliografia Citada}


ALENTEJANO, "Pluriatividade: uma noção válida para a análise da realidade brasileira?" in TEDESCO, J. C. (org.) Agricultura familiar: realidades e perspectivas. Passo Fundo: EDIUPF, 1999.

ALVES, Eliseu, LOPES, Mauro, CONTI, Elísio. “ $\underline{O}$ empobrecimento da agricultura brasileira.” Revista de Política Agrícola. Brasília, ano 8, n.3, p.13-25, jul.-set. 1999.

BRASIL. Ministério do Desenvolvimento Agrário. Agricultura familiar, reforma agrária e desenvolvimento local para um novo mundo rural. Brasília: 1999.

CARVALHO F', José Juliano. "Política agrária do governo FHC: desenvolvimento rural e a Nova Reforma Agrária.” in LEITE, Sérgio Pereira. (org.) Políticas públicas e agricultura no Brasil. Porto Alegre: Editora da Universidade/UFRGS, 2001.

LESBAUPIN, Ivo. (org.). O desmonte da nação. Petrópolis: Vozes, 2000.

LESBAUPIN, Ivo e MINEIRO, Adhemar. O desmonte da nação em números. Petrópolis: Vozes, 2002.

LOPES, Eliano Sérgio Azevedo. Comentário sobre o "Novo Mundo Rural” ou a "Nova Reforma Agrária” do Governo FHC. Sergipe, 1999. (Mimeogr.).

MARTINS, José de Souza. Reforma agrária - o impossível diálogo. São Paulo: Edusp, 2000.

MEDEIROS, Leonilde Servolo de. Banco da Terra: disputas em torno dos sentidos da bandeira "reforma agrária". Rio de Janeiro, Unrisd, 2002.

TEIXEIRA, Gerson. A realidade das metas, e o fracasso da estratégia política do Programa de Reforma Agrária do governo FHC. Brasília: ABRA, 2002. 